REIS, João José; GOMES, Flavio dos Santos; CARVALHO, Marcus J. M. de. O alufá Rufino: tráfico, escravidão e liberdade no Atlântico Negro (c. 1822-c. 1853). São Paulo (SP): Companhia das Letras, 2010.

\title{
Um Alufá, o tráfico, a escravidão e a liberdade no Atlântico Negro
}

\author{
Sabrina Fernandes Melo ${ }^{1}$
}

O livro Alufá Rufino é resultado de quase dez anos de intensa pesquisa em diversos arquivos, regiões e países, trabalho realizado por seus autores e também por uma ampla rede de contatos criada por eles ao decorrer dos anos de estudos. A escrita desta obra foi feita por mais de duas mãos, ela juntou historiadores importantes nos estudos de escravidão.

João José Reis, considerado por muitos como um dos principais historiadores do Brasil é especialista em estudos relacionados a história social e cultural da escravidão, história do Brasil, resistência escrava e movimentos sociais no Brasil durante o século XIX. É graduado em história e ciências sociais, possui doutorado pela University of Minnesota e atualmente é professor do Departamento de História da Universidade da Bahia. Dentre suas principais publicações destacam-se: A morte é uma Festa, Rebelião Escrava no Brasil e Domingos Sodré.

Flávio dos Santos Gomes é graduado em História e Ciências Sociais, possui doutorado em História Social pela UNICAMP e atualmente é professor é professor colaborador do Departamento de pós-graduação da Universidade Federal do Rio de Janeiro e da UFBA. Flávio já desenvolveu pesquisas sobre o Brasil colonial e pós-colonial, escravidão, Amazônia, fronteiras e campesinato negro. Atualmente trabalha com história comparada, cultura material e escravidão no Brasil, América Latina e Caribe, especialmente

\footnotetext{
${ }^{1}$ Mestranda em História pelo Programa de Pós Graduação em História da Universidade Federal de Santa Catarina. Bolsita CAPES. E-mail: sabrina.fmelo@gmail.com

${ }^{2}$ REIS, João José. A morte é uma festa: ritos fúnebres e revolta popular no Brasil do século XIX. São Paulo (SP): Companhia das Letras, 1991. Rebelião Escrava no Brasil: a história do levante dos malês em 1835. São Paulo: Companhia das Letras, 2003. Domingos Pereira Sodré, um sacerdote africano: escravidão, liberdade e candomblé na Bahia do século XIX. São Paulo: Companhia das Letras, 2008.
} 
Venezuela Colômbia, Guiana Francesa e Cuba. Sua principal obra publicada, além do Alufá Rufino, é sua tese de doutorado: $A$ bidra e os Pantanos ${ }^{3}$.

O terceiro autor do livro é Marcus de Carvalho, professor titular de história da Universidade Federal de Pernambuco, pós-doutor pela École de Hautes Études en Sciences Sociales. Seus temas de pesquisa estão relacionados com a escravidão, o tráfico de escravos e a história social do chamado "ciclo das insurreições liberais do Nordeste", sua principal obra publicada é Liberdade ${ }^{4}$.

Em o Alufá Rufino nota-se o diálogo e as perspectivas de pesquisa de cada um dos autores. O livro é dividido em três partes. A primeira parte aborda o contexto político do Reino de Oyó, local onde o personagem central, Rufino, nasceu e viveu até os dezessete anos até ser capturado e trazido para o Brasil como escravo. São abordados também os conflitos políticos da Bahia, local onde Rufino desembarcou e foi comprado pelo Boticário João Gomes da Silva servindo a este senhor como cozinheiro e possível ajudante em sua botica, local em que pode ter aprendido o manuseio e fabricação de remédios, conhecimentos que posteriormente podem ter sido aplicados em outros locais em que Rufino esteve. Nessa primeira parte, a contextualização da Bahia é bem fundamentada, e assim pode-se supor que João Reis contribuiu muito na escrita e pesquisa desse contexto geográfico e temporal.

A segunda parte do livro, trata principalmente do período em que Rufino já está liberto e atua como cozinheiro em navios negreiros, em um período conturbado e perigoso no Atlântico, já que o tráfico de escravos se encontrava na ilegalidade e sob vigília constante da marinha inglesa. A pesquisa de Flávio dos Santos associa-se a esta questão do Atlântico, a história comparada e aos estudos do tráfico durante o período ilegal.

A terceira parte conta a história de Rufino já estabelecido em Recife, local que escolheu para viver após suas andanças e aventuras por mar e por terra, onde se tornou Alufá e conselheiro espiritual. O autor Marcus Carvalho possui vasta experiência em pesquisas sobre escravidão em Pernambuco, o que contribuiu para a escrita e pesquisa mais detalhadas desta parte do livro.

Já no prefácio do livro, os autores deixam claro que não se trata apenas da biografia de Rufino, a proposta vai mais além. O personagem Rufino é utilizado como uma espécie

\footnotetext{
${ }^{3}$ GOMES, Flávio dos Santos. A Hidra e os Pântanos: Mocambos e quilombos no Brasil Escravista. São Paulo: Editora UNESP, 2005.

${ }^{4}$ CARVAlHO, J. M. de. Liberdade: Rotinas e Rupturas do Escravismo, Recife, 1822-1850. Recife: Editora da UFPE, 1998.
} 
de guia, de fio condutor e de parâmetro na delimitação do recorte temporal e espacial da pesquisa. A partir da história de Rufino e da documentação encontrada, os autores percorrem os caminhos trilhados por ele e tentam entender os diversos contextos e as especificidades destas diferentes localidades (que se diferenciam espacial, temporal e culturalmente). Os documentos utilizados como ponto de partida para a construção da narrativa do livro são dois. O primeiro é o inquérito policial e o depoimento de Rufino, que foi preso e investigado em Recife a partir de suspeitas de seu envolvimento com revoltas de escravos. O segundo é um artigo publicado por uma das testemunhas presentes em seu interrogatório no jornal O Commercio. Este artigo, segundo os autores, foi escrito por uma pessoa com perfil abolicionista, já que em diversos trechos nota-se que o escritor defende e até acha justo que o acusado seja libertado e tenha a possibilidade de proferir sua fé. Rufino era muçulmano letrado e no Brasil esse grupo de africanos era conhecido como malês.

Os autores transitam entre os diferentes espaços que Rufino percorreu e a partir da documentação procuram reconstruir sua história, que muitas vezes não é mais a história central do livro, já que a documentação especifica sobre Rufino é limitada. Dessa forma, os autores buscam informações sobre pessoas próximas a Rufino, para então exercer o que se chama de "imaginação histórica", ou a elaboração de questionamentos e de conjecturas pautadas na verossimilhança. Os autores trabalham com as possibilidades sempre pautadas e bem delimitadas por documentos que se aproximam de Rufino, trabalhando com analogias e buscando outros personagens que se aproximariam da realidade social e cultural do personagem central.

A aventura de Rufino começa na Bahia. Nesta cidade ele atuou como escravo doméstico sendo cozinheiro na casa de um boticário que fabricava remédios para uma das instituições filantrópicas mais importantes da cidade naquele período, a Santa Casa de Misericórdia. Rufino vivia no recôncavo baiano, região de grande heterogeneidade étnica e cultural. Devido a diversidade de povos que habitava este espaço, é possível, segundo os autores, que Rufino tivesse contato com grupos de malês que estudavam o corão, e que posteriormente seriam acusados de liderar uma revolta escrava na Bahia, porém, quando eclode essa revolta, ele já se encontrava no Rio Grande do Sul.

Sua viagem para o Rio Grande do Sul ocorreu na companhia do filho do Boticário, que era militar. $\mathrm{O}$ motivo desta viagem é incerto e não foram encontrados documentos a esse respeito. Rufino teve dois donos em Porto Alegre, o primeiro foi um comerciante que faliu e fugiu para Montevidéu, e Rufino foi leiloado em hasta pública. Seu segundo dono no 
sul foi o chefe de polícia Peçanha, um influente e poderoso político local, que concedeu a alforria à Rufino em meio aos conflitos da Revolta Farroupilha.

Não há muitos vestígios de como foi a vida de Rufino no Sul, porém esse momento foi crucial para o desenrolar de toda a história que estaria por vir. Entretanto, os autores não abordaram muito essa parte, deixaram algumas lacunas que poderiam ter sido preenchidas no intuito de um maior entendimento do período em que Rufino viveu nessa região. A questão da urbanização da cidade de Porto Alegre bem como a história do clube malê, do Rio Grande, receberam pouca atenção dos autores. Essas são questões cruciais que moldaram a vida de Rufino, que foi um escravo urbano, viveu em cidades portuárias com muita movimentação de pessoas e circulação de ideias.

Por transitar em diferentes espaços e continentes, e por ter sido escravo urbano, Rufino teve acesso a diferentes espaços de sociabilidade, a diferentes culturas e pessoas. Tornou-se assim um poliglota com aguçada visão cosmopolita sempre envolvido com as questões políticas dos lugares pelos quais passava. Em seu depoimento temos prova de seu conhecimento político quando o Alufá baseia sua estadia nos diferentes locais a partir de eventos políticos importantes, como foi o caso de sua chegada à Bahia durante a Revolta do Madeira e sua saída de lá antes da volta de Dom Pedro a Portugal.

Após a conquista de sua alforria em Porto Alegre, Rufino segue para o Rio de Janeiro. Não se sabe ao certo como chegou até o Rio e porque ele escolheu essa cidade, que se encontrava bastante tumultuada e os escravos muito perseguidos após o medo exagerado causado por rumores de uma possível insurreição escrava. Os autores apresentam uma história alternativa pautada no possível envolvimento de Rufino em um clube malê no Rio Grande e sua possível deportação junto com um outro escravo forro, denominado José. Na documentação de deportação consta o nome de dois escravos: Rufino e José, deportados por participarem de atividades suspeitas. Contudo, não se sabe se esse Rufino seria o mesmo, o nosso Abuncare do Reino de Oyó.

Rufino não ficou muito tempo no Rio de Janeiro, talvez pela grande perseguição e pelo medo que rondava a cidade, talvez porque realmente tivesse sido deportado e em seguida conseguiu de alguma forma livrar-se dessa pena. No Rio de Janeiro, já liberto, Rufino "decidiu” trabalhar como cozinheiro em navios negreiros. Visitou Serra Leoa por duas vezes, local onde aprimorou seu árabe e seus estudos corânicos. Uma das paradas em Serra Leoa foi forçada, devido a captura do Ermelinda navio no qual Rufino trabalhava e foi possivelmente um pequeno comerciante, levava seus doces de goiaba para serem vendidos 
nos portos africanos. Há indícios também da atuação de Rufino como pequeno traficante de escravos, negociante e intermediário destas transações.

O Ermelinda foi capturado a partir de uma lei unilateral criada pela Inglaterra para dar fim ao tráfico ilegal. A chamada "Lei do Equipamento" tinha por objetivo capturar os navios que estavam equipados para receberem cativos. Eram verificados pela marinha inglesa os números de tonéis para armazenamento de água, a carga de comida, o porão do navio, dentre outros aspectos. O navio em que Rufino se encontrava foi considerado como "boa presa", como possível navio negreiro e, portanto, apreendido e julgado pela comissão mista com sede em Serra Leoa.

O navio foi inocentado, graças a pressão por parte do governo brasileiro que alegava não haver provas suficientes para sua condenação. O caso do Ermelinda tornou-se famoso por ser o único barco inocentado pela comissão mista. Além disso, as apreensões acabaram se tornando um negócio lucrativo tanto para os oficiais da marinha como para Inglaterra, pois os navios apreendidos eram leiloados e os oficiais que capturavam recebiam uma comissão em dinheiro que variava de acordo com o carregamento. O pagamento era mais alto quando continha carga humana e por esse motivo, muitos oficiais faziam "vistas grossas" durante o carregamento nos portos, e mais tarde faziam a apreensão em alto mar do mesmo navio liberado por eles. A maioria destes cativos era deixada em Serra Leoa, abrigo que inicialmente surgiu como um projeto filantrópico de Colônia de Liberdade, mas que de liberdade tinha pouco.

Após a liberação do Ermelinda e do pedido de indenização por parte dos tripulantes desta embarcação, Rufino volta para o Brasil e decide se estabelecer em Recife, local onde ficaria conhecido como Alufá. Nesta cidade ele é preso e interrogado por possuir escritos suspeitos, revolucionários. A partir deste episódio os autores perseguem todo o rastro de Rufino, que já comentamos. Em seu depoimento ele conta os lugares pelos quais passou, aparentando, pelo seu discurso, ser um homem pacato e preocupado em proferir sua fé e atender seus diversos clientes - dentre eles homens brancos - da melhor forma possível. A tentativa dos autores de apresentar um perfil revolucionário a Rufino durante todo o livro se desmancha na última parte, onde o personagem é apresentado como sereno e acima de qualquer suspeita revolucionária.

Esta obra apresenta um grande exercício de erudição e de pesquisa histórica, além disso, uma boa referência de como se trabalhar as fontes, para exercer a imaginação histórica e as conjecturas, delimitadas pelas fontes existentes. A obra diz muito sobre essa 
nova forma do fazer histórico, que busca histórias individuais, mas que não se fecham nelas, mas ampliam o foco, e muitas vezes utilizam a "lupa", o "microscópio" na tentativa de apreender o macro e o micro, de entender os contextos e o sujeito, de conjecturar possibilidades e de imaginar, historicamente, aquilo que não está dado. 